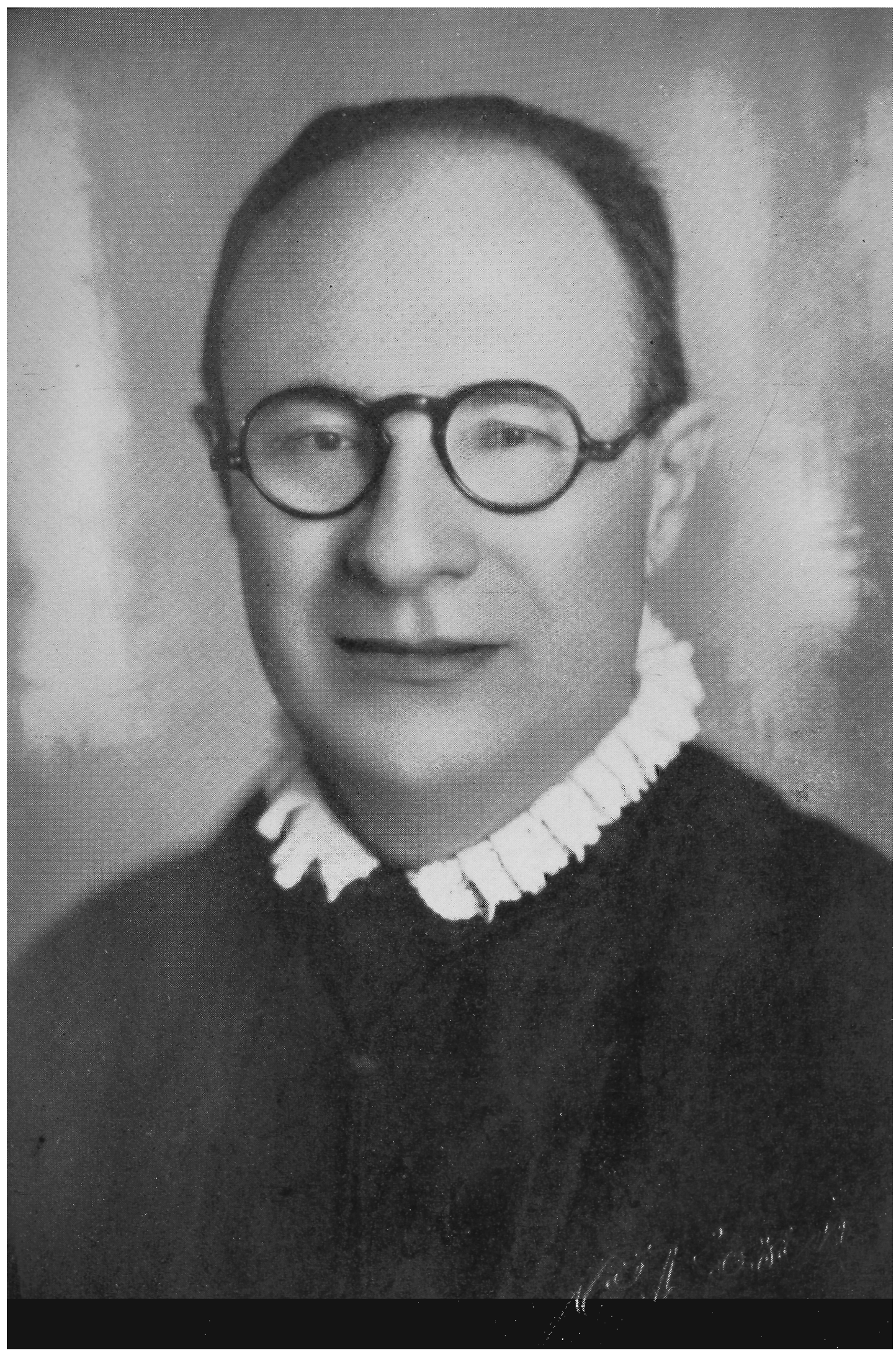




\section{Professor Braz de Souza Arruda}

\section{Redação}

1 - 0 professor BRAZ DE SOUZA ARRUDA nasceu aos 3 de fevereiro de 1895, na cidade de Campinas, onde seu pai, o eminente professor João ArRudA, era então Juiz de Direito. $\mathrm{Na}$ família de que descende, figuram, entre outros nomes ilustres, os de seus tios Braz Barbosa de Oliveira Arruda, luiz Barbosa da Silva e Antonio Barbosa da Silva, o de seu avô dr. Braz Barbosa da Silva, seu bisavô comendador antonio Barbosa da Silva, bem como os dos dezembargadores Barbosa nogueira e Inácio Arruda (do Tribunal de São Paulo), e o do dr Euzébio Barbosa de Queiroz Matroso, todos antigos alunos da Faculdade de Direito de São Paulo.

Criado em Ribeirão Preto, fez exame de admissão ao Ginásio do Estado, cursando, a seguir, o Ginásio Silvio de Almeida, de onde se transferio para o Ginásio de Ciências e Letras, naquela época dirigido por Luiz Antonio dos SANros. Concluidos com brilho os estudos propedêuticos, prestou exame de ingresso à Faculdade de Direito, exame para cujo êxito concorreu, sem dúvida, a orientação que lhe pro-porcionou, nos seus estudos de Filosofia e Latim, o preclaro mestre João Mendes Júnior. Éste último, bem como PEDro Lessa e João Arruda, foram, ao que diz o prof. Braz ARR:UdA, os seus guias espirituais.

No curso acadêmico, onde teve por colegas de turma amilcar de Castro, Flávio Guimarães, Ciro de Freitas Valle, Julio de Mesquita Filho, Plínio Balmaceda Cardoso, Mario de Souza Lima, Plínio Gomes Barbosa, José da Costa Silva Sobri- 
NHO e outros, destacou-se, por seu amor ao estudo, como, aluno sempre distinto e sempre premiado. Colou grau em 1916.

2. Em 1917, logo depois de formado, disputou em concurso, a cátedra de Economia Política, Finanças e Direito Administrativo. Sua aprovação, unânime, valeu-lhe o título de livre docente da Faculdade.

Apresentou-se de novo a concurso, em 1919, para as cadeiras de Direito Internacional Público, Direito Internacional Privado e Direito Constitucional. Aprovado e classificado em primeiro lugar, fixou-se, por decreto de 1925 , na cadeira de Direito Internacional Publico, que rege. Desde então até hoje, tem também ensinado, em caráter interino, quase tôdas as demais disciplinas, inclusive as do curso de doutorado, ao tempo em que êste funcionou.

3. A política interessou-o desde a vida acadêmica, durante a qual ocupou mesmo o cargo de secretário do Centro Acadêmico Onze de Agosto. Tomou parte, então, nos diversos movimentos cívicos da época, mórmente quando a mocidade se erguia para formar ao lado de RÚi BARBosA. Posteriormente, batalhou com a juventude das escolas superiores paulistas pela candidatura de Luiz Pereira Barreto. No Partido Democático, bateu-se ativamente pelo triunfo da revolução de 1930. Em 1932, apesar de doente, manifestou solidariedade para com a revolução constitucionalista.

4. Em relação à cadeira de Direito Internacional, que ocupa, o mais importante trabalho do professor BRAZ DE Souza Arruda é a série de preleções por ele feitas no curso de doutorado, e que, sob o título de "Estrutura do Direito Internacional", esta Revista publicou no fascículo II do volume 34 (1938), e reeditou no fascículo III do volume 36 (1941). São 138 páginas substanciais, de riquissima erudição e de aguda crítica. "Limitam-se, geralmente, os professores de Direito Internacional a ensinar princípios consagrados (diz o A.) e a defender os interêsses dos poderosos; 
não concorrendo em nada para o progresso do ramo do Direito que ensinam. 0 mestre honesto e conciencioso deve criticar o Direito Internacional existente, e obrigar o aluno a refletir sôbre seus principios fundamentais." Fixada assim a sua atitude, examina o $\mathbf{A}$. os tópicos essenciais da disciplina, quer na sua feição didática, quer na sua evolução histórica.

5. Outra produção do professor Braz de Souza Arruda, justamente louvada, é a que versa o problema de "A Mulher na Diplomacia", com que encerrou os cursos jurídicos da Faculdade de Direito, em 21 de novembro de 1931 (Revista da Faculdade, volume 27). Examina o assunto ajudado por inexgotável erudição, e firma ponto de vista inteiramente a favor da admissão da mulher na função diplomática. "GAMA Lово (escreve ele), após enumerar casos de mulheres diplomatas, diz que os nossos hábitos e a educação que damos às mulheres, parecem reprovar a admissão destas pessoas para o exercício das funções diplomáticas. Essa objeção é fraquissima, pois argumentava GAMA LoBo com a educação das mulheres portuguesas de seu tempo, beatas, cheias de preconceitos obsoletos, estcravizadas ao homem, esquecendose contudo de que há paises em que as mulheres são educadas e livres, e outros em que, são mais instruidas do que os próprios homens: - haja vista os Estados Unidos." Mais adiante, declara ainda: "A diplomacia nada mais é do que a aplicação da inteligência e do tacto às relações entre os Estados e a arte de conciliar os interêsses do país com os do Estado junto ao qual o agente está acreditado, e com os da sociedade cosmopolita, cultivando um espírito, uma mentalidade internacional. Ora, para realizar esta missão, parece-me, nada falta à mulher: - inteligência e tacto, eis as qualidades essenciais ao diplomata". A êste propósito, assevera mesmo: "Em um ponto, a mulher é superior ao homem, no tacto, na habilidade, na astúcia, no que poderiamos chamar - Maquiavelismo, e no seu horror 
à violência, à brutalidade, no amor profundo à paz: — qualidades fundamentais para a diplomacia."

6. Neste e em outros trabalhos, toma o professor Braz DE Souza Arruda posição definida contra a guerra. "A guerra ameaça o mundo, e a guerra futura será o cemitério da civilisação", diz êle em 1931, citando Hoover (quando ainda ninguem pensava na bomba atômica). A seguir, apoiando Henri le Wita, afirma, muito antes dos bombardeios de Varsóvia, de Rotterdam, de Londres ou de Colonia: "a luta entre as nações, que era até há pouco feita entre forças armadas, será de hoje em diante dirigida contra os não combatentes, contra as populações inermes." Por isso, "é necessário acabar com a guerra, pô-la fora da lei, e isso só será possível pela educação e esclarecimento das massas, pelo desenvolvimento de uma opinião pública mundial contra a guerra, pela formação do espírito internacional, pela tríplice aliança dos intelectuais honestos, das mulheres e da mocidade."

7. Preocupação também frequente no professor Braz Arruda é a que se relaciona com a educação em todos os níveis, desde o elementar até o universitário. Em "O Problema Universitário", de 1929, escreve: "Nenhum progresso em matéria de ensino é possível enquanto predominar entre nós o sistema de reformas parciais, mormente feitas por pessoas que desconhecem os mais rudimentares princípios da pedagogia." $E$, mais adiante: " $E$ ' preciso difundir o ensino primário, contando-se com uma ação conjunta da união e dos estados, do municipio e dos particulares." Tratando da escola secundária, diz: "Na escola secundária vai (o menino) desenvolver o seu espírito e habilitar-se para um ofício (função seletiva)." Nessa escola, "nada de programas formidáveis e indigestos." “A educação consistirá principalmente em desenvolver a reflexão, o espírito crítico, o raciocinio, o amor ao estudo, à leitura. Nada de preleções." 
Quanto ao grau superior, "seria absurdo para as universidades ficarem isoladas no meio das comoçöes e transformações que se operam nos povos; não são máquinas de doutorar, mas sim crisol de homens, focos de pensamento renovador e de fôrças espirituais." "A universidade deve socializar a cultura e vincular os povos." Será necessário renovar os processos didáticos: “o seminário significa uma nova orientação, que Fichte caracterizou dizendo que sua finalidade é formar o espírito cientifico." "A importância do seminário é enorme, pois o livro tornou inútil a universidade clássica."

Nesse mesmo trabalho, mostra-se favorável à participação dos alunos na direção das universidades, e fixa, como uma de suas conclusões: "estabelecer os cursos de seminários, desenvolver a investigação, abolir os exames finais e os concursos..." No ano, ainda, de 1929, relatando um parecer sôbre sugestões do Centro Acadêmico Onze de Agosto (parecer que os profs. Waldemar Fereira, Vicente Ráo e Sampaio Doria subscreveram), oferece-se, com tôda a comissão, "para, de acôrdo com os estudantes, iniciar desde logo a reorganização da biblioteca e as medidas indispensáveis para a adoção dos novos métodos nesta Academia, por meio de conferências, inquéritos, análises de livros e revistas, da confecção e discussão de teses, etc."

8. Da extensa bibliografia do professor Braz de Souza Arruda, foi-nos possivel reunir os seguintes títulos, os quais, como se vê, abrangem os mais variados assuntos: Discursos Acadêmicos, cujo volume, de 1916, foi dedicado ao prof. Raphael Sampaio; Direito Administrativo e Ciência da Administração (tese de concurso, 1917); Deve o salário do operário ser proporcional à renda da terra e ao proveito do capital? (tese de concurso, 1917); uma série de artigos, reunidos no volume n. 21 de Revista da Faculdade de Direito: A crítica de M. Lascure ao meu ilustre mestre dr. Almeida Noqueira; Ação social do Estado sôbre a Instrução Pública; $O$ intercâmbio intelectual com as Repúblicas america- 
nas; Repugna ao Direito Internacional o uso dos submarinos de guerra?; Pode o estrangeiro divorciado "a vinculo" em seu país contrair nupcias no Brasil?; o Connor d'ARLACH; Da troca, sua noção e definição; A união pode impor aos estados um alistamento para as eleições locais?; Importa a naturalização do pai a do filho menor?; Os grandes problemas econômicos; $O$ melhor sistema tributário; $O$ projeto do dr. Sampaio Vidal; $O$ interêsse econômico em relações internacionais; Apólices de renda perpétua; Empréstimos; O instituto do perdão; O projeto do senador HERculano de Freitas; Em relação à parede dos operários; Antigo São Paulo; Discurso ao ser dado à Biblioteca da Faculdade um exemplar da conferência de Rur Barbosa em Buenos Aires; Eleições; Conferências patrioticas; A santa cruzada; A responsabilidade alemã pela conflagração européa; Os crimes e as loucuras dos alemães; A conflagração européa estudada do ponto de vista econômico; Deve o salário do operário ser proporcional à renda da terra e ao proveito do capital?; Papel moeda; "Post bellum"; Crises econômicas; Direito Internacional Público; O reclamo; Estado de sítio e eleições (em colaboração com o prof. João ARRUdA); no vol. 22 da mesma Revista: Socialismo harmônico e a questão social; Danos por operações de guerra; Discurso que deveria ter sido pronunciado na Faculdade de Direito de São Paulo na recepção do dr. Epitácio Pessoa, e que não foi por motivo de fôrça maior; no volume 23: O centenário da Faculdade de Direito; Resumo das preleções de Direito Internacional Público; Guerra Civil; Progresso e futuro do Direito Internacional; Organização de partidos; O divórcio; volume 25: Parecer sôbre as sugestões do Centro Acadêmico Onze de Agosto; A vida rural na Inglaterra (tradução); O problema universitário; volume 26: Discurso de paraninfo; volume 27: A mulher na diplomacia; volume 34: Estrutura do Direito internacional; volume 36; re-edição do trabalho anterior; volume 37: Crueldades nas guerras. Muitos desses trabalhos haviam sido 
publicados anteriormente, em jornais e revistas, ou tiveram neles posterior reprodução.

9. Sôbre a forma lisongeira por que foram acolhidas, no País e no estrangeiro, as produções do professor BRAZ de Souza Arruda, leiam-se, no volume 21 da Revista da Faculdade de Direito, as elogiosas cartas recebidas por ele ou por seu pai, das seguintes personalidades: Alcrisiades RoLdán (Chile); Estanislad Zeballos (Argentina); Henry Campbell Black (E. Unidos); Josephus Jitta (Holanda); Eduardo Espinola (Brasil); José Leon Suarez (Argentina); Carvalmo de Mendonģa (Brasil); J. Lobo d'Avila Lima (Portugal); Juan Agustin Garcia (Argentina); Oliveira Lima (Brasil); Conde Afonso Celso (Brasil); e Azevedo Marques (Brasil). 